\title{
From e-Mediation to On-line Restorative Justice in Criminal Law
}

\section{Oscar Daniel Franco Conforti}

Department of Criminal Law and Department of Restorative Justice, School of Law, University Center of Baja California, Tijuana, Mexico

\section{Email address:}

franco.conforti@gmail.com

\section{To cite this article:}

Oscar Daniel Franco Conforti. From e-Mediation to On-line Restorative Justice in Criminal Law. American Journal of Engineering and Technology Management. Vol. 2, No. 5, 2017, pp. 56-63. doi: 10.11648/j.ajetm.20170205.11

Received: September 4, 2017; Accepted: September 23, 2017; Published: November 2, 2017

\begin{abstract}
One of the fields in which conflict mediation is developing is on the Internet where it will, no doubt, become one more tool used to resolve conflict, regardless of the nature of the dispute, whether internet related or not. The legal framework in Spain allows us to clearly differentiate On-Line Mediation from other online dispute resolution (ODR) methods. This article reviews the state of on-line mediation, and further defines what is meant by electronic mediation and also proposes certain parameters for the On-line Restorative Justice Process.
\end{abstract}

Keywords: On-line Restorative Justice, On-line Mediation, Electronic Mediation, E-mediation, Mediation by Electronic Means, ODR, On-line Dispute Resolution, On-line Mediation in Spain

\section{Introduction}

The Directive 2008/52/CE of the European Parliament and of the Council, May 21st, 2008, on certain aspects of mediation in civil and commercial matters [1], intended to encourage amicable dispute resolution through mediation and highly recommend this process to resolve cross-border disputes in civil and commercial matters. This Directive was the first step taken by the European Union (EU) to promote on-line mediation.

A legal framework in Spain was established under Law $5 / 2012$, of July 6th, on Mediation in Civil and Commercial Matters (the Mediation Act), published in the Official Gazette of the Spanish State on July 7th, 2012. This Act entered into effect on July 27th, 2012 [2]. The Mediation Act was followed by Royal Decree 980/2013, of December 13th, which expanded on certain aspects of Law 5/2012, of July 6 th, regarding mediation in civil and commercial matters (the Regulation Act) [3].

The EU is dealing with two different legal systems existing within its member states, Common Law and Continental or Civil Law- The objective of EU Directives is to harmonize the domestic law of each member state. This is a huge challenge which, in fact, has not yet been achieved yet.

The concept of mediation as used in each text will be examined and compared, keeping in mind certain philosophical differences under the two legal traditions.

Under Common Law, the idea of justice, involves processes intended to provide each party the opportunity to prevail in a dispute. There is, generally, one decisional level in court, its judgment usually becoming definitive unless appealed before a higher court.

Under Continental Law, the State, rather than the parties themselves, assumes control of the investigation into a case. It is a multilevel decisional system, in which parties can obtain a range of different decisions or verdicts [4].

A Common Law system is an egalitarian system developed in a horizontal level, in which mediation as a conflict resolution methodology works in perfect harmony (or at least without conflict) within the legal system. Continental Law, however, provides a vertical system where court decisions can change the outcome of litigation at each jurisdictional level; here mediation will encounter greater challenges to its introduction and development due, above all, to motions requesting judicial review [5].

These functional or philosophical differences between the two systems will be relevant to examine the nature of on-line mediation in greater detail. 


\section{What On-line Mediation Means in the EU and in Spain}

The origins of on-line dispute resolution can be found in the development and subsequent boom in on-line commerce. The growth of retail websites such as e-bay, Amazon, etc., gave rise to the need to develop new ways to deal with inevitable disputes. On-line purchases, returns and complaints all required new ways of resolution. For a deeper analysis of these developments see E. Katsh, J. Rifkin and A. Gaitenby, 'Ecommerce, E-disputes, and E-disputes resolution: In the Shadow of eBay law'[6].

On-line dispute resolution is young; and it could be said that it was identified as a new field of traditional alternative dispute resolution when it was defined as such by Ethan Katsh and Janet Rifkin in the above-referenced paper. ODR facilitates dispute resolution thanks to the transforming power of technology. In fact, technology has become a fourth party within the traditional three-party model (the two parties and a neutral) of alternative dispute resolution [7].

Almost all authors coincide in stating that the consideration of the technology as the fourth party, has only just begun. "Whether we will ever see computer programs capable of adjudicating complex disputes, or walking parties through a mediation to resolution, seems like the stuff of science fiction at this point." [8].

The European Commission followed with a report in 2002 titled Green Paper (concerning the alternative modalities of dispute resolution in the field of civil and commercial law). The Commission focused on trade and commerce and the natural areas of disputes arising from them: collections, claims, contract compliance, etc. The aim of this paper was to identify legal issues arising out of the new methods or alternatives available to member states in the field of civil and commercial law as applied to alternative dispute resolution.

In the European context, this report laid the groundwork for the development and use of ODR methods and technologies. European legislators understood that future legislation regarding conflict resolution arising out of EU commerce should include and encourage the use of new internet technologies. Having concluded that ODR could and should be of use in commercial disputes, the Green Paper ended questioning how member states would incorporate this new method within their traditional, established legal systems. The report asked in question No. 3: "whatever initiatives must be taken, should they treat differently the methods of on-line dispute resolution (ODR) - a raising sector characterized by innovation and a fast evolution of new technologies, with all the particularities it entails- and traditional methods?, or should they refer to both methods without discrimination instead?"

Subsequent EU directives would go on to make explicit reference to on-line dispute resolution (ODR) methods. We do not find a clearly expressed preference for any particular method. They do, however, make clear that mediation is not applicable to consumer matters [1].

Following the same criterion, the Spanish Mediation Law does not allow mediation in consumer disputes (Law 5/2012, art. 2). However, the Law in Spain went further than the Directive establishing the on-line mediation process as a specific method (arts. 5, 24 and final provisions 4 and 7 of the Law 5/2012 and arts. 30 to 38 of the Regulation Act 980/2013). This indicates that Spanish legislators recognized intrinsic differences between ODR in general and On-Line Mediation as a specific method.

\section{Distinguishing Between ODR and On-line Mediation}

It is essential to make clear distinctions between these concepts given the legal responsibilities (both civil and penal) of the mediator (Law 5/2012 arts. 9 and 14). These legal issues will be examined in greater detail further on.

One of the elements used by authors was the concepts synchronous and asynchronous. "The current state of technology does not allow a widespread use of videoconferencing, except for large cases. Teleconferences are sometimes used as a supplemental means of communication, but online mediation is usually limited to emails and webbased textual communications-chat rooms for synchronous communications and bulletin boards for asynchronous communications." [9], but this is not enough to set a criterion.

Other authors recognized the on-line mediation as a particular sub-field of ODR. "Writing on e-mediation as one discrete element in the field of ODR is a sign of the field's maturing." [10]. But unfortunately a clear definition of emediation is lacking in the article.

This is the first step needed to examine the components of ODR to then understand the issues relating to on-line mediation. If we move from ODR as a general concept to online mediation as a more specific method, a natural paradigm for this study is that of genus and species.

The main group, which we have labeled as genus contains many elements, which are only limited by the technology on offer. They include: e-mails, text messages, chats, fora, video messages, videoconferences, etc. Looking at these technical elements, it is possible to form groups based on the complexity of each tool. Therefore, e-mails, chats and SMS can be considered as simple when used by parties, while a videoconference falls in the category of sophisticated. The graph illustrates this concept.

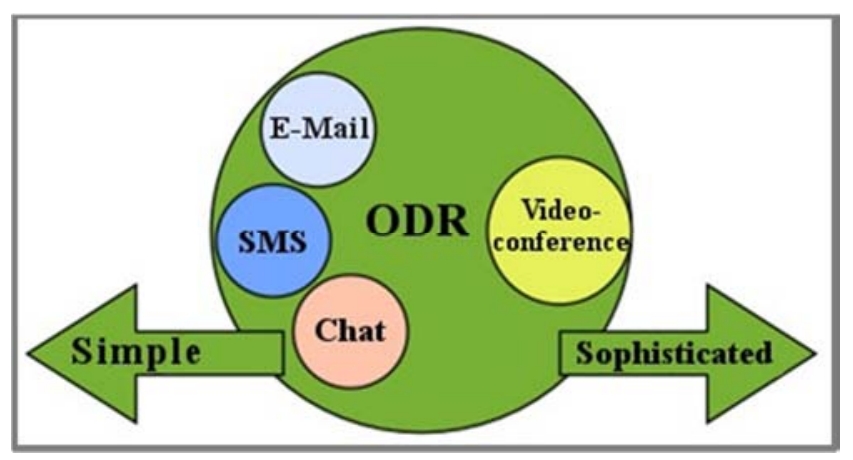

Figure 1. General Presentation of Genus and Species. 
If we build upon this rather basic scheme and introduce other elements, we must include asynchronism and synchronism as means of communication between parties and the mediator.

The following graph shows the increasing number of elements in the ODR process providing an indication of possible concerns arising out of confidentiality and security issues. In this graph, called the ODR tree, the tree as genus would naturally include various species such as On-Line Mediation, but here the emphasis is on the technical components.

There are four leaves. The two fallen leaves on the left and right side of the tree correspond to asynchronous and synchronous modalities respectively. The large leaf on the tree at the top marks a division between simple and sophisticated ODR. The smaller leaf (in the middle of the tree) separates public videoconference from private videoconference.

The different technical elements identified in the circles have been grouped by colors according to their proximity to either asynchronous or synchronous criteria. In the asynchronous group on the left, (e-mail, sms, fora, and document management) the element chat is placed higher and closer to the tree trunk because it can be used either asynchronously or synchronously.

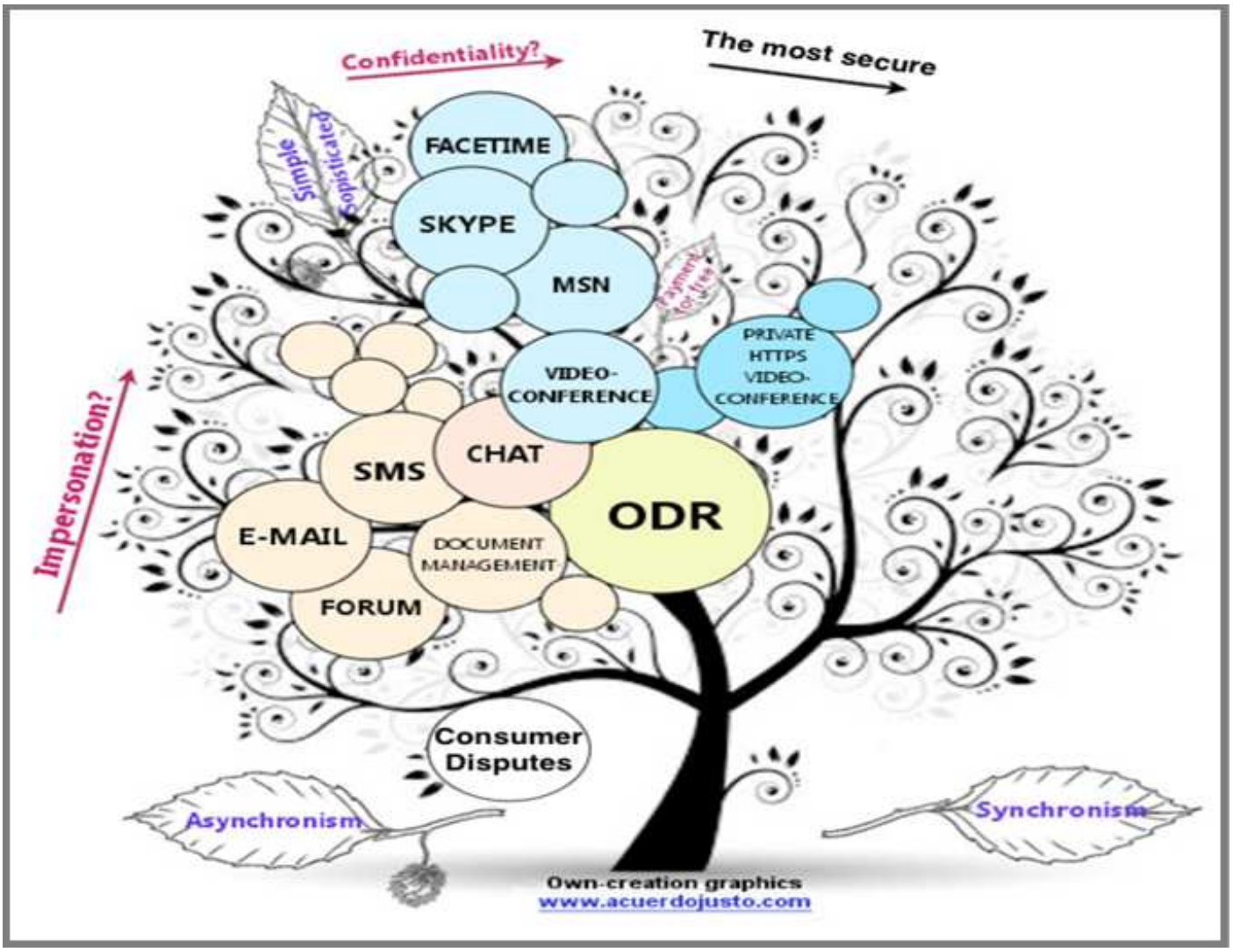

Figure 2. ODR Tree [11].

The more sophisticated technical elements, such as videoconferences in their different forms appear on the right side of the tree. In a stronger color tone, private http videoconference is the furthest to the right side, because it is the only tool that provides the mediator with greater certainty in meeting the security requirements of a mediation process.

HTTPS (also called HTTP over TLS, HTTP over SSL, and HTTP Secure) is a protocol for secure communication over a computer network which is widely used on the Internet. HTTPS consists of communication over Hypertext Transfer Protocol (HTTP) that involves a connection encrypted by Transport Layer Security or its predecessor, Secure Sockets Layer. The main motivation for HTTPS is authentication of the visited website and to protect the privacy and integrity of the exchanged data.

The outer arrows around the tree indicate the problems or difficulties that each group of elements or species faces.
For example, the simple ODR group has serious difficulties avoiding identity impersonation. On the other hand, the group of more sophisticated ODR tools requires making a distinction between (i) public videoconference providers, like Skype, having similar problems in terms of confidentiality and secrecy as the simple ODR group; and (ii) private videoconference providers, suppliers operating under the https protocol, which today is considered the most secure way to carry out an on-line mediation [11].

As mentioned before, everything related to consumer disputes takes a different direction, since it is prohibited in the Directive 2008/52/EC number 11. As a consequence, the term ODR is used in the Proposal for a Regulation of the European Parliament and of the Council on on-line dispute resolution for consumer disputes (Legislative Resolution of the European Parliament, March 12th, 2013), but it is excluded at the national level as per Art. 2.d) Law 5/2012. 
That's why it has been placed in a small circle on the branch below.

Ethan Katsh has said, "As Professor Conforti understands, the phrase online dispute resolution (ODR) is an umbrella for many different approaches to resolving disputes. All ODR processes share some common goals in that the communications systems employed need to be trusted and accessible. All ODR systems also share some challenges such as when choices need to be made between synchronous and asynchronous forms of communication. There are, however, also differences in that there are laws that apply to particular forms of dispute resolution and not to other forms. This book provides clear guidance about the legal context for e-mediation" [11].

Having established a distinction between the genus and the species regarding On-Line Mediation, On-Line Mediation will be examined next.

Because e-mediators will have to go beyond theories and models in each on-line mediation they handle, it can be expected that they will draw upon a variety of techniques, tools, approaches and knowledge. But while e-mediators become effective in applying many different techniques and technologies in the mediation process, two factors will remain paramount: (i) law and regulation acts governing mediations, and (ii) principles of mediation.

In accordance with Spanish Law 5/2012 and Royal Decree 980/2013, mediation processes must be developed according to the following legal rules:

a) Voluntary and Free Disposition to Participate (Art. 6)

b) Equality of the Parties and Impartiality of the Mediator (Art.7)

c) Neutrality of the Mediator (Art. 8)

d) Confidentiality (Art.9)

e) Good Faith, Respect, and Cooperation (Art.10)

f) Safeguarding the Identity of the Participants (Art. 24.1)

In addition, the e-mediator must be sensitive to specific characteristics of the on-line mediation process:

g) Interaction Means Action Exerted Reciprocally [11], Meaning (i) Dialogue Between Each Party and the Emediator in a Preliminary Session, or (ii) Between the Parties and the E-Mediator Which must be Synchronous to be Considered Interaction, at Least in Accordance with Mediation Principles

h) The E-Mediator must Apply all Mediation Techniques at his Disposal to Deal Effectively with Emotions and Empowerment, to Recognize the Key to Transformation in Conflict, to Focus, Reframe, Summarize-review, to Allow Narratives and Talk About Feelings, Responsibility, to Ask Appropriate Questions to Identify Unmet Needs Behind no, to Give Homework for the Next Session, to Help the Parties Visualize and Reach Their own Boundaries, to Calm High Emotions by Respecting and Validating Them, to Redirect the Dialogue, etc

i) The E-Mediator must Observe the Parties Closely. Visual Contact with Them will Allow him to Read Body Language Such as Reactions, Predisposition to Cooperate, Low or High Interest, etc. Above all, the E-Mediator is the
Person who can Verify the Identities of the Parties Through Visual Contact

In conclusion, On-Line Mediation is a process which can be accomplished wholly or partly by electronic means in a more or less simple way, in which the identity of the parties must always be protected and verified, and which must be conducted in accordance with the principles and characteristics of the mediation process as provided by Law, and which will always be conducted by an e-mediator, a trained neutral third party able to help parties reach an agreement by themselves [12].

Restorative Justice is an important contemporary expression of timeless standards of justice; while it is true that the On-line Restorative Justice Process should be an ODR (which emphasizes accountability, making amends, and facilitates meetings between victims, offenders, and other persons) due to its specificity it is highly recommended to follow the e-Mediation rules in order to ensure the quality of the process.

\section{Legal and Non-legal Difficulties in On-line Mediation and On-line Restorative Justice Process, and Their Solutions}

In Spain, there is no legislation with regard to the On-line Restorative Justice; however, by analogy it is advisable to follow the principles of e-Mediation.

There are four major challenges or difficulties; two of them are legal in nature, while the other two are of a more procedural one.

Regarding legal issues there are possible criminal offenses that could arise out of on-line mediation. These are found in articles 197.5 and 199 of the Spanish Penal Code regarding confidentiality (secrets disclosure) and article 401 of the same Law regarding identity impersonation (civil status usurpation) and they are:

a) Confidentiality (Art. 9 of Law 5/2012)

b) Guarantee of the Participants' Identities (Art. 24.1 of Law 5/2012)

Regarding procedural issues, it is important to bear in mind that if the following aspects of an on-line mediation are not satisfied, the endeavor may, in fact, take on the characteristics of something else, called negotiation, counseling, etc., but not on-line mediation:

c) Interaction (the Mediation Process is Synchronous)

d) Mediation Techniques and Skills (Deal with Emotions)

The process must include interaction to allow the emediator to apply techniques used in a standard mediation.

Each of these four challenges to on-line mediation will be examined in greater detail.

According to Spanish law, the mediator is responsible for maintaining confidentiality and the guarantee of the parties' identities. How will mediators ensure that these aspects are complied with? Challenges regarding confidentiality have much to do with the technology employed, specifically with 
cloud computing systems.

Many cloud systems are management and/or electronic document processing systems that allow users to access information kept in the provider system as if it were Skydrive, Dropbox, etc. This means that any document (opening statement, commitment to further mediation sessions, and/or final agreement) has to go through an intermediary, meaning the company providing the service to be stored or saved in a place in the cloud.

At the start, before any choice is made, the mediator must explain to the parties how this works and what it entails to the parties. Once it is understood and agreed to by the parties, the e-mediator can transfer information to the Internet cloud system provider; otherwise, the process must stop there.

The concept of fifth party was introduced by Bol and Lodder. The fifth party represents the provider of the technology. This concept has been developed to explain the various possible relationships between the parties involved in the ODR process. According to Lodder and Zeleznikow "The fifth party is not a legal party; it is a technical player in the ODR process, namely the provider of dispute resolutions services" [13]. This point of view is not shared by some authors, due to the significant differences between the law regulations form one state to another [14].

The mediator may require that parties sign an agreement authorizing him to upload and manage information. This agreement will be valid under the law. However, there are two points to bear in mind: how will this practice affect the mediation and the level of trust necessary to further the mediation process? Secondly, does the validity of the agreement mean that the mediator is not liable for any violation of confidentiality, even in a criminal matter?

These concerns can be easily overcome when the emediator uses desktop software. These are resident programs or applications which are previously installed in the computer of the mediator, or mediation centre. The mediator manages all information, documents, and sessions with the parties as if the parties themselves were an office package such as Microsoft Office, iWork, Open Office, etc.

The mediator will be the only person with full access to the program or application; this means that the e-mediator will collect, handle, and keep all information, thereby ensuring that no mistakes are made. The e-mediator has to become an expert at using software in order to perform this process properly. In this way, mediators can avoid typical setbacks such as when the company server does not respond or shows error messages.

The second legal challenge concerns protecting and guaranteeing the parties' identities.

Is an Electronic ID a possible solution? First, while the European Union has been working on this matter [1], a unique electronic identity certification has not been materialized for all member states yet. The technology is available, but unified standards have not been achieved yet [12].

Second, the mere fact of having an electronic ID attached to an individual does not prevent its unauthorized use by another. In this respect, an electronic ID is not unlike a credit or cash card. In the end, mediation on-line requires visual contact: we need to see the person. Visual confirmation of identity is the only way to avoid this problem [13].

Is it possible then to conclude that the use of videoconference is the simple solution? The answer is yes, but not with free videoconference providers in an open environment such as Skype [14]. This service does not guarantee the privacy or confidentiality of communications. Also I must call readers attention to the fact that all communications through United States Servers are scanned by different agencies of the US government. The US government has acknowledged access to Google, Facebook and Skype (among others). See The Washington Post [15], and The Guardian [16].

In fact, open videoconferencing providers expressly exclude any and all responsibility regarding the privacy of the service they provide (see clause 12 on terms of use or contracts conditions of this free services) [14]. A further complication is added in that the Law requires that mediation sessions be registered or recorded by the e-mediator for possible future audits [1].

The remaining non-legal challenges to on-line mediation previously identified included the need for interaction between parties and mediator, and the employment of the necessary techniques and skills by the mediator characteristic of mediation processes.

With regard to interaction we can conclude that mediation must be a face-to-face meeting between the parties. The technical ability to provide the vital element of synchronized communication exists, so why would it not be carried out in this manner, thereby guaranteeing the necessary degree of interaction?

As for mediator and facilitator's skills, it is possible to conclude that with the appropriate platform within which to conduct an on-line mediation or an on-line restorative justice process, mediators and facilitators are able to use and apply all of their techniques. In other words, they will be able to deal with emotions, read body language, ask questions and elicit responses while allowing for reframing or paraphrasing.

As Professor Ethan Katsh said "Much of the writing on ODR from the United States neglects these topics; both offline and online mediation in the U.S. are informal and less subject to data protection and other types of European-based directives" [12].

\section{How an On-line Mediation Process in Spain Works}

There are two phases to an on-line mediation in Spain. The first consists of necessary documentation including, but not limited to an application or invitation letter to mediate, caucus session reports, an initial joint mediation session report, and a final joint mediation session report. These documents, or paperwork, will now be filed electronically and will be maintained by the mediator in his computer. At 
this stage, the mediator will use desktop software to handle, manage and store files, thereby guaranteeing privacy and confidentiality.

The second phase involves actual mediation sessions with parties. This phase becomes more complicated in that the technology used must address the issues that we have already identified as essential to the process: privacy, confidentiality, identity security, and the ability of mediators to use and apply mediation techniques.

These components of the process, which have been broadly outlined, will be explained in greater detail.

Applications to mediate may be submitted in person or in an on-line form, collected in a web-form with or without certification of digital identity, or may be submitted by mutual agreement by both parties to the conflict, or simply submitted unilaterally by one of them.

Upon receipt of the application, the mediation centre or emediator may contact the moving party to either obtain additional information (in the case of application by one of the parties), or to hold a preliminary hearing at which time he would inform the applicant of the on-line mediation process. Once the e-mediator has all the relevant information, he can initiate contact by any means (letter, fax, phone, e-mail, etc.), including inviting the other party (required) to participate in the on-line mediation process.

Informative and/or preliminary sessions in the form of videoconference may be held with one or both parties, jointly or separately, depending on the circumstances of each case as the e-mediator deems necessary. These hearings will address many procedural issues, covering the nuts and bolts of the process. During this preliminary hearing, the mediator will disclose to the parties any circumstance likely to raise doubts regarding independence and impartiality. The nature and characteristics of mediation will be explained along with fees and expenses. The procedural system to identify the parties, including electronic signature technology, will be established. The mediator will also establish deadlines, explain the extent and purpose of record-keeping, and explain the possible legal consequences arising from a mediated agreement. At this time, the parties are afforded an opportunity to ask questions and discuss any concerns they may have.

The opening joint hearing consists of interactive videoconferencing which shall include the identification of the parties and the mediator, system accreditation and identification, and the authentication and validation of the parties' digital signature agreement. The objectives of the mediation process will be defined, along with and an estimate regarding the duration of the mediation, costs and form of payment. A declaration of voluntary submission to mediation by the parties, location and language to be used will be confirmed. At this point video recording starts with live, real time interaction between the parties and the mediator.

There are two informative sessions (one for each one of the parties) and two or three joint sessions, as well as a session should one or both parties wish to discuss their agreement with their lawyers before signing it.

In Spain the first platform to provide on-line mediation was Mediar On-Line (www.mediaronline.com) [17]. Since 2008, it has offered a process that relies on appropriate desktop software to maintain the electronic record of the proceedings, together with a videoconference system that follows https protocols to ensure privacy and security. This service was developed with the support of the Family Mediation Centre, Justice Department of Catalonia Generalitat.

\section{Execution of Cross-border Agreements in Conflict Mediation Within the EU}

The European Union actively promotes the use of alternative methods for conflict resolution (ADR), and, in particular, mediation. The primary aim is to promote the use of mediation in member states to help alleviate an overburdened court system. By encouraging the use of mediation to make conflict resolution easier, it is hoped that this alternative will be generally accepted, thereby diminishing the waste of time and money associated with traditional litigation, while at the same time ensuring that citizens are able to pursue their rights effectively.

To this end, the legal instrument that the European Union has adopted is found in the Directive 2008/52/EC on Mediation, which should have been implemented by the Member States by May 2011. This Directive regulates mediation in commercial and civil matters.

The Mediation Directive is to be used in cross-border lawsuits in commercial and civil matters. It applies to disputes where at least one of the parties is domiciled in a member state different from the other partie's when agreeing to mediate, or on the date a court orders mediation.

To achieve the above mentioned objectives, the Directive established five independent rules:

a. It mandates that Member States promote the training of mediators to ensure quality and expertise in mediation;

b. It empowers judges (if they consider it appropriate in a particular case) to invite parties to a dispute to consider mediation;

c. It stipulates that, if the parties so request, the agreement(s) resulting from mediation become binding instruments. This can be achieved, for example, through the approval of the agreement by a court or its certification by a public notary;

d. It guarantees confidentiality in the mediation process, stipulating that mediators cannot be forced to testify in court about what transpired during mediation in a future conflict between the same parties;

e. It guarantees that the parties do not waive their right to a trial while they attempt to resolve their dispute through mediation, since statutory deadlines for filing a lawsuit are suspended during the process of mediation.

The following regulations must be considered and taken into account in order to obtain the execution of agreements in Europe: 
f. Council Regulation (EC) No. 44/2001, 22nd December, 2000, on Jurisdiction, Recognition and Enforcement of Judgments in Civil and Commercial Matters (Brussels I): the decisions adopted in a Member State of the European Union (EU) will be recognized in all Member States without resorting to any proceedings, except in case of opposition.

g. Council Regulation (EC) No. 2201/2003, November, 2003, on Competency, Recognition and Enforcement of Judgments in Matrimonial Matters and of Parental Responsibility, Regulation (EC) No. 1347/2000 (Brussels II): automatic recognition of decisions concerning visitation rights.

The number of conflicts brought to courts is increasing everywhere, leading both to longer waiting periods to obtain a court judgment, and rises in trial costs to the point where in many cases costs are not proportional to the economic value of the dispute. In a recent judgment a court in Barcelona imposed a fine to one of the parties because they had not tried an alternative dispute resolution method, such as mediation, before going to trial. In this judgment act the value of the judicial process was fixed at $2.600 €$ in 2012 , nowadays this amount is higher [18].

On-Line Mediation is a reality despite current differences in the European Union between mediation methods and matters subject to mediation. However, this method of conflict resolution is becoming more attractive as an alternative to litigation.

On-Line Mediation and On-Line Restorative Justice process are challenging for those who work in the field of legal technology and conflict management. To deny its existence and importance means to ignore the future.

\section{Conclusion}

In Spain, ODR and On-Line Mediation are different issues. ODR is a wide field which uses information technology to facilitate the resolution of disputes between parties. Involves methods and process carried out completely on-line, and in which the presence of a third party named neutral is not necessary at all in order to allow the parties to reach an agreement by themselves. It is a genus.

On-Line Mediation is a process which can be accomplished wholly or partly by electronic means in a more or less simple way, in which the identity of the parties must always be protected and verified, and which must be conducted in accordance with the principles and characteristics of the mediation process as provided by Law, and which will always be conducted by an e-mediator, a trained neutral third party able to help parties reach an agreement by themselves. It is an specie.

Restorative justice repairs the harm caused by crime. When victims, offenders and Community members meet to decide how to do that, the results can be transfomational. There is no reason to deny the possibility of carrying out an on-line restorative justice process.

The on-line restorative justice process relies on technology that is easy to use providing necessary privacy and security. The facilitator will rely on appropriate desktop software to maintain the electronic record of the proceedings, together with a videoconference system that follows https protocols.

Facilitators need to develop new skills and ethics in his practice on line, because they need to be aware that they are working on two levels at the same time: the level of the novel capabilities of the tools employed and the level of the legal consequences of employing this technology.

\section{References}

[1] European Union. (2008). Directive 2008/52/CE of the European Parliament and of the Council, May 21st, 2008 on certain aspects of mediation in civil and commercial matters. European Union Official Journal, Strasburgo, May 24th, 2008. L. 136, pp. 3-8. Available on Internet at $<\mathrm{http} / /$ eurlex.europa.eu/legal-

content/EN/ALL/;jsessionid=SQsnTGGQCkyHvdGVLGw7P mzLpX8TPR7TfGRgGzcQJvRv8ThLw4L4!794013655?uri= CELEX:32008L0052>. [Visited: May 28th, 2014].

[2] Spain. (2012). Law 5/2012, of July 6, on Mediation in Civil and Commercial Matters (the "Mediation Act"), was published in the Official Gazette of the Spanish State on July 7th, 2012 and entered into force on July 27, 2012. Available on Internet at $<$ http://www.boe.es/boe/dias/2012/07/07/pdfs/BOE-A-20129112.pdf $>$. [Spanish version, visited: May 28th, 2014].

[3] (2013). Royal Decree 980/2013, of December 13th, for develop certain aspects of Law $5 / 2012$, of July 6 th, mediation in civil and commercial matters (the "Regulation Act"). Available on Internet at $<$ http://www.boe.es/diario_boe/txt.php?id=BOE-A-201313647>. [Spanish version, visited: May 28th, 2013].

[4] Damaska, M. R. (2000). The Faces of Justice and State Authority: A Comparative Approach to the Legal Process, (original title published in Chile: "Las caras de la justicia y el poder del estado: análisis comparado del proceso legal.") Santiago de Chile: Editorial Jurídica de Chile.

[5] Conforti, O. D. F. (2014b). 'Impact of effective judicial protection on the model of conflict mediation in Spain' in Confluencia Magazine: analysis, experiences and conflict management. (title original: 'Impacto de la tutela judicial efectiva sobre el modelo de mediación de conflictos en España' en Revista Confluencia: análisis, experiencias y gestión de conflictos"). Bogotá, no 10, pp. 125-154.

[6] Katsh E., Rifkin J. and Gaitenby A. 'Ecommerce, e-disputes, and e-disputes resolution: In the shadow of "eBay law". Ohio State Journal of Dispute Resolution 15, pp. 705-734. Available on Internet at $<$ http://www.umass.edu/cyber/katsh.pdf $>$ [Visited: January 28th, 2014].

[7] Katsh E., and Rifkin J. (2001). Online Dispute Resolution. Resolving Conflicts in Cyberspace. San Francisco: JosseyBass.

[8] Rule C. (2002). Online Dispute Resolution for Business. San Francisco: Jossey-Bass.

[9] Kaufmann-Kohler G., and Schultz T. (2004). Online Dispute Resolution. Challenges for Contemporary Justice. The Netherlands: Kluwer Law International. 
[10] Ebner, N. (2012), 'e-Mediation', in Abdel Wahab, M. S., Katsh E. and Rainey D. (Eds.) Online Dispute Resolution: Theory and Practice, pp. 357-386, The Hague: Eleven International Publishing, 2012.

[11] Bohm, D. (1996). On dialogue, (original title published in Spain: "Sobre el Dialogo".), Barcelona, España: Kairos.

[12] Conforti, O. D. F. (2014). Electronic Mediation Handbook. Alicante, España: Acuerdo Justo.

[13] Lodder A. R. and Zeleznikow J. (2010). Enhanced Dispute Resolution Through the Use of Information Technology. The Edinburgh Building. Cambridge. Cambridge University Press.

[14] Skype. (2014). Terms of Use. Available on Internet at $<$ http://www.skype.com/en/legal/tou/ >. [Visited: May 28th, 2014].

[15] Paterson A. (2013). 'PRISM already gave the NSA access to tech giants. Here's why it wanted more'. The Washington Post, October 30th, 2013 26. Available on Internet at $<$ http://www.washingtonpost.com/blogs/theswitch/wp/2013/10/30/prism-already-gave-the-nsa-access-totech-giants-heres-why-it-wanted-more/>. [Visited: May 28th, 2014].

[16] The Guardian. (2014). 'The NSA Files'. The Guardian. Available on Internet at $<$ http://www.theguardian.com/world/the-nsa-files $>$ [Visited: May 28th, 2014].
[17] Sanz Parrilla M. (2001). 'The use of electronic media in mediation', in Helena Soleto Muñoz, Mediation and Resolution of Conflicts: techniques and fields. (original title: "El uso de medios electrónicos en la mediación, en Helena Soleto Muñoz, Mediación y Resolución de Conflictos: Técnicas y Ámbitos.”) Madrid, Tecnos.

[18] Barcelona court, $<\mathrm{http}: / /$ www.sepin.es/visor/default.asp?referencia=SP/NOT/6 53> ví, March 20th, 2015.

\section{Biography}

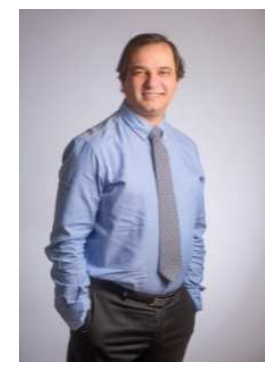

Oscar Daniel Franco Conforti, Ph.D in Law, with both Italian and Argentinean citizenship. Department of Criminal Law and Department of Restorative Justice, School of Law, University Center of Baja California, Tijuana, México. Lecturer in Negotiation at the Open University of Catalonia. Member of the Research Group on Mediation and Social Intervention at the University of Alicante. Master's Degree in Mediation (UNED) and specialist in Organizational Conflicts by the Florida International University of Miami (FIU), USA. Director of Acuerdo Justo ${ }^{\circledR}$, Consultant in Conflict Management and Ex-Director of the Communitary Social Mediation Service of the City Hall of Alicante, Spain. 